\title{
Virtual and Augmented Reality in Public Archaeology Teaching
}

\author{
Kate Ellenberger
}

Two of the biggest challenges in public archaeology teaching are getting interlocutors' attention and getting them to feel connection to past people. Inspiring focus and empathy in the short interactions we have can be difficult, especially when the subjects are very distant in time. New and scholarly produced forms of virtual reality show particular promise for getting and keeping the attention of our publics. In this review, I discuss several forms of virtual or augmented reality and assess them as tools for public archaeology practice.

Virtual reality (VR) and augmented reality (AR) are commonly understood as technologies of display (of images, environments, etc.) that sit along a spectrum of constructed realities (Milgram et al. 1995). VR is the term used to describe replacing human consciousness with constructed surroundings. If you put on a headset with a video game or other virtual world rendered within it but cannot see your body's physical surroundings, you are experiencing virtual reality. (Although it is beyond the scope of this review, deeper critiques of the immersiveness, interactivity, and sensoriality of VR use in archaeology have been produced at length [Eve 2012, 2017; Graham et al. 2015; Morgan 2009, 2016]). In contrast, $A R$ refers to situations in which a digital device is employed to modify your normal surroundings. Google Glass and Pokemon GO (Figure 1) are both popular examples of augmented reality, where information (e.g., a picture of a video game character) is projected on top of your regular scope of vision. In AR, human sensory experiences are changed or added to, not replaced. Both VR and AR have different technological and pedagogical qualities.

Studying the effect of immersive experiences that use archaeological themes is not new; nor was it spurred on by the recent availability of virtual reality headsets on the mass market. Work in archaeological phenomenology has challenged the traditional boundaries of archaeological practice to incorporate a personal and embodied approach to researching past people's experiences (Eve 2012; Sims 2009; Tilley 1994; Van Dyke 2007, 2008). Media archaeologists have studied and created representations of archaeology in film as well (Insole and Piccini 2014; Rogers 2016). There are compelling pedagogical works about the power of gamification and other experiential forms of teaching, where learning outcomes become goals that students can visualize and complete through the mechanism of games (Arya et al. 2012; Copplestone 2014; Foreman et al. 2004). Now that there are open-access, low-cost tools available to make virtual and augmented reality models, more archaeologists are creating and using such technologies to reach the public through experiential learning. Projects range from static models of individual objects to entire landscapes that translate aspects of memory, phenomenology, and materiality into virtual or augmented reality experiences (e.g., Lithodomos VR 2017; Paleowest Archaeology 2016; Virtual Curation Museum 2013).

Below, I describe three specific forms of virtual and augmented reality that can be used in public archaeology, and I outline positive and negative aspects of each. I will discuss viewing individual artifact scans on Sketchfab, exploring immersive landscape models, and using an augmented reality phone application to enhance documents. I have used each of the examples during public archaeology teaching and consulting work. Hence, I base my analysis, in part, on real-world experience. I address budget, ease of use for practitioners and the public, wow factor, and portability for each, in addition to relaying my experiences.

\section{ARTIFACTS IN 3D}

According to recent scholarly work, interfacing with artifacts either physically or virtually has "direct implications for people's experience with, and understanding of, ancient artefacts" (Giuseppantonio Di Franco et al. 2016:184), and there is evidence that virtually manipulating digital versions of artifacts may be more effective than observing authentic artifacts that cannot be handled (Giuseppantonio Di Franco et al. 2015). Decontextualized original artifacts are staples in public archaeology teaching, but while they inspire curiosity, people are often shy to pick them up and explore them. Three-dimensional VR reconstructions seem to inspire similar curiosity in visitors without fear of breaking the objects or appearing impolite by treating them too roughly. One of the largest collections of free, open-access 3D artifact scans is on the British Museum's page on Sketchfab (British Museum 2014). There are over 175 models on their profile page, made by the digital humanities team, who have scanned objects in the museum's collection (Deniau 2017a, 2017b, 2017c).

Advances in Archaeological Practice 5(3), 2017, pp. 305-309

Copyright 2017 이 Society for American Archaeology

DOI:10.1017/aap.2017.20 


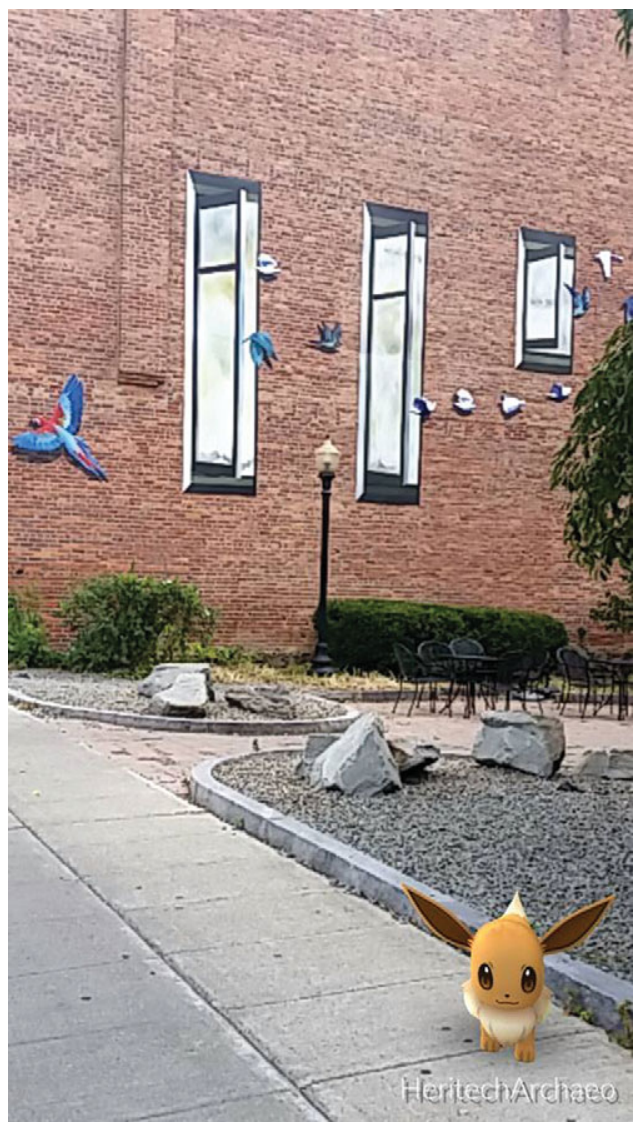

FIGURE 1. Viewing this public park in Pokemon GO, I see a wild Evee inviting me to catch it and gain experience in the game. Historic markers and other points of interest are also marked in the game, and visiting them is incentivized. Screenshot of Pokemon GO (Niantic, Inc.) by author.

If a visitor clicks on a single object, they will visit a page with information on the item and an interactive 3D representation, which they can manipulate with a cursor or by using a touch screen. The site is usable on any device with Internet access. Every model can be viewed using a virtual reality headset (Sketchfab 2017), including the low-cost Google Cardboard. Viewing an artifact in VR can be as easy as going to the website on a smartphone, clicking a button, placing the phone inside Google Cardboard, and looking inside. This form of VR can be done for free on any Internet-connected device, or viewed through a VR headset, costing between $\$ 20$ and $\$ 800$ (U.S.).

I have experimented with showing students aged 8-12 virtual reality models of artifacts in a class setting and received positive feedback overall. The tension surrounding the handling of artifacts is nonexistent, and when working with children or other members of the public with lower dexterity, the VR format liberates them from some agility-related difficulties they might face interacting with original artifacts. Another benefit is that using a VR headset forces students to focus on the artifact, blocking out distractions and causing them to be more attentive to spoken information. The wow factor of virtual reality also draws people in more than conventional artifacts, in my experience. My efforts in presenting archaeology at table events and other forms of outreach suggest that VR engagement works well outside of the classroom too.

However, there are definite challenges to teaching with such models. The textures, light-responsive qualities, and weights of genuine artifacts all inform how we identify them, and it is more difficult to communicate those multisensory observations to the public when we use intangible versions of artifacts. Replacing tangible artifacts with VR does not allow us to model careful artifact handling, which may be a key goal for some public archaeologists. Still, presenting virtual artifacts is a good option for settings where physical artifacts are not available or appropriate, or for practitioners who do not have access to a teaching artifacts collection.

Also important to consider is the fact that many archaeologythemed models on the Sketchfab site that do not disclose the original artifact's legal owner or how they came to model it. If a model does not have adequate citation, there is no way to know whether it was created illegally or via breaching common disciplinary ethical codes, or whether the original artifact was obtained illegally or unethically (see Nicholas et al. 2010 for more details on intellectual property issues in heritage management). So I strongly recommend that colleagues research the author of the 3D model before using it, and I suggest the British Museum as a good starting point because they have been transparent about ownership and the appropriate use of their models.

\section{VIRTUAL LANDSCAPES}

The most common form of virtual and augmented reality used in archaeology is the virtual landscape model. Digital landscape models have been popular research tools and outreach mechanisms for some time, with recent critiques and projects focusing on creating interactive experiences rather than static or representational snapshots of a reconstructed past (Morgan 2009). The promise of virtual landscapes for public archaeology is that we can communicate with the viewer about the human experiences of past people beyond their stuff; in my opinion, the projects that focus on this goal are the ones that are most potent for teaching. There are a limited number of archaeologistcreated, interactive landscape models for colleagues to try, due to the specialized labor required to make and maintain them. One well-documented example of an archaeologist-built virtual landscape is Virtual Rosewood (Gonzalez-Tennant 2011, 2013), a representation of the African American town of Rosewood, Florida, in 1922, just before racial and economic tensions came to a head in the Rosewood Riot. The virtual town memorializes the inhabitants' way of life in a way the physical town no longer can, incorporating Gonzalez-Tennant's archaeological research and descendants' oral histories (Gonzalez-Tennant 2011). Exploring Virtual Rosewood, viewers can walk around a vast landscape of houses, stores, and landscape features, reading relevant signs (Figure 2). The VR experience is particularly informative if the viewer is familiar with the aftermath of the Rosewood Riot; exploring the model makes it easier to visualize the space where the riot took place, and by extension, the changes it caused in people's lives.

The practical difficulties of using landscape-level VR in public archaeology are its main drawback. Most scholarly produced 


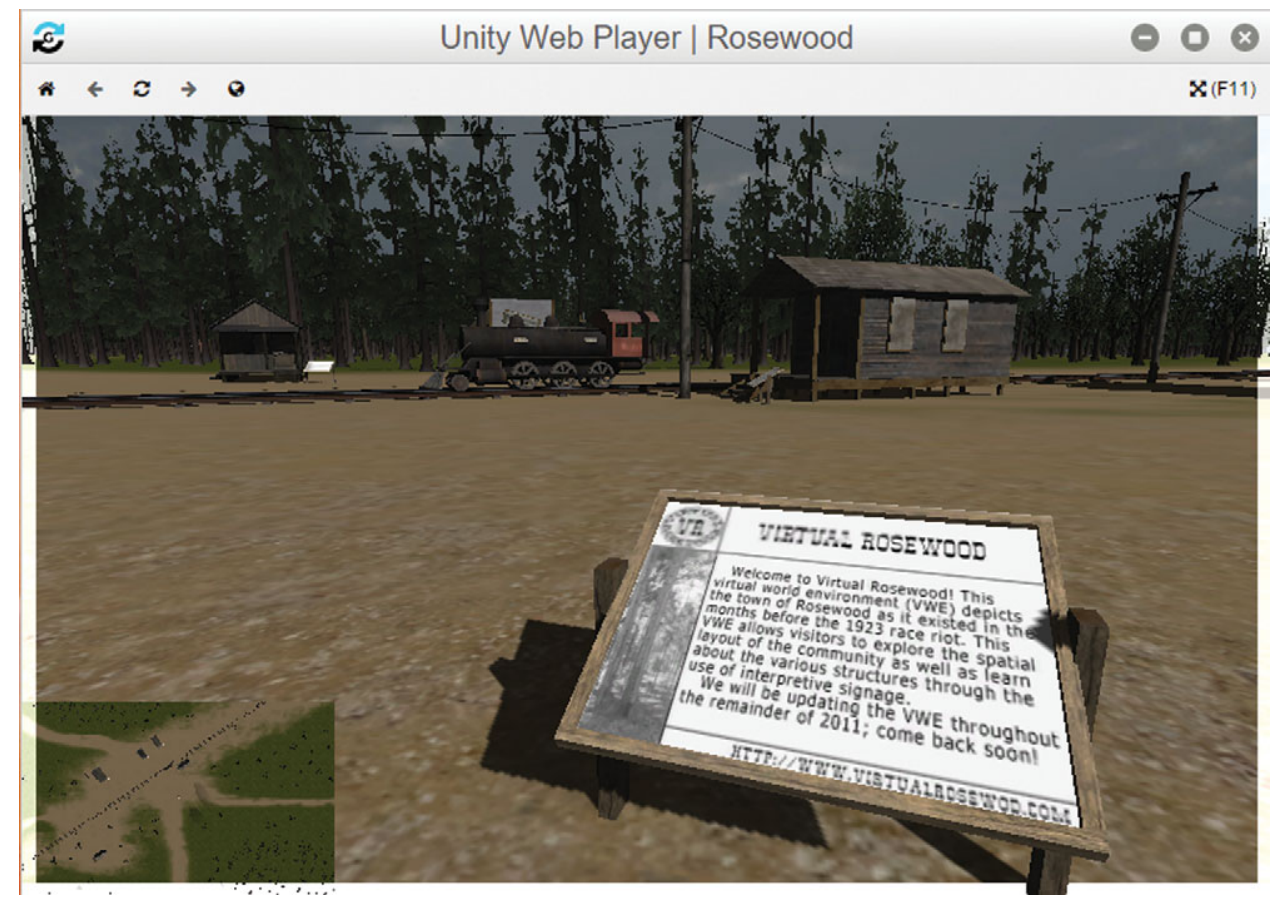

FIGURE 2. Virtual Rosewood is a large space full of homes, shops, and signs that recount the memories of residents before the town's riot took place. Screenshot of Virtual Rosewood by author.

landscape models will run only on a computer (or a powerful mobile device) and are comprised of large files to download or require substantial Internet bandwidth to run. Many models hosted online are currently not usable without workarounds; creators must contend with the transition to new technical requirements in order for their 3D models to be viewable in web browsers, which requires financial and labor investment to overcome. These access restrictions may require enough cost or labor to rule out landscape VR for most event-based public archaeology. In teaching, it can be difficult to incorporate landscape models into lessons because most of them do not have sufficient interactivity. In my experience, unless clicking has a clear reward, people express embarrassment that they do not understand how the model works or what it means. Still, there is promise for landscape models as tools for drawing together multiple sources and voices of archaeological research for public consumption.

\section{AUGMENTED REALITY}

Anyone with a smartphone can use AR to project historical photos and other media onto the world around them using free applications like Clio (Trowbridge 2017) or Harvard University's Point of Interest Visual Optimization Tool (PIVOTtheWorld, Inc. 2016). As easy as these apps may be to use, they are not focused on archaeological principles, and most are limited to a small geographic area. Archaeologist-produced projects like Voices Recognition (Eve et al. 2014), a multisensory tour of York Cemetery, leverage AR to share archaeological information, memories, and phenomenology. Augmented reality need not take the form of a tour, however, as digital archaeologist and historian Shawn Graham has shown in his Diary in the Attic project (2015), which adds layers of sound and visuals while the viewer reads pages from an anonymous nineteenth-century diary by a woman traveling the Nile (also provided by him). Although it is a proof of concept at this stage, Graham has made the Android app, code, and authoring information freely available so colleagues can create their own versions more easily (Graham 2015).

Although augmented reality is a new focus in heritage disciplines compared to the VR topics discussed above, it seems particularly useful for public archaeology teaching. Archaeologists who lead tours or set up table displays could use AR to enrich their surroundings with media that are more easily updated than permanent exhibits and do not require changes to physical facilities. For static items like a building, or in Graham's project, the pages of a historical diary, one can add new movement and sound. I expect that this technology would not be as useful in a lecture, but in most situations, being able to provide a literal "archaeological lens" when we are teaching sounds tantalizing.

The main difficulty in applying AR in public archaeology is that it takes significant expertise and resourcing to realize these projects. Still, within our discipline there are many scholars working with this technology, and AR projects such as Diary in the Attic are smaller and more scalable than landscape-level VR models. One minor concern I have for document-based AR, based on Diary in the Attic, is that it obscures the text of the document (see the text in the background of Figure 3). This problem of obscuring critical content is consistent with my experience using other AR apps: it seems to be a feature of them and not a glitch. It is easiest to read the document on its own and use the AR app as a magnifying glass, to get additional detail not seen without assistance. Compared to viewing individual objects on a smartphone, AR is only slightly more difficult to use as a teacher or viewer. 


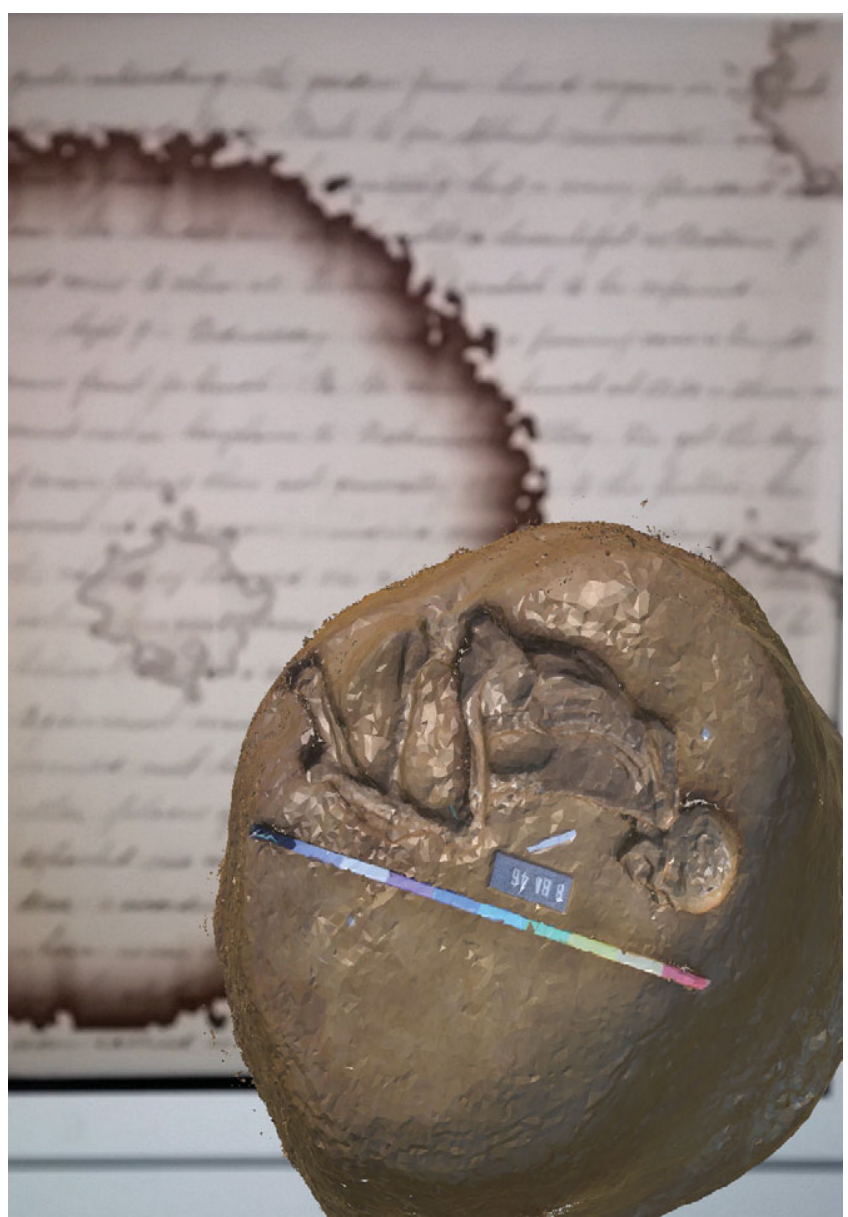

FIGURE 3. While scrolling through the Nile diary using Diary in the Attic, ambient desert sounds play and this 3D model of a human burial appears on the screen. Screenshot by author.

\section{CONCLUSION}

Virtual and augmented reality are promising tools we can use to inspire members of the public to focus and empathize with past peoples. The VR and AR projects of fellow archaeologists have shown us new ways to present our archaeological lessons, and novel ways to tie them all together, if we are willing to experiment. The long-term success of programs like the Campus Archaeology Program (2017) at Michigan State University and the Florida Public Archaeology Network (2017), among many others, has been achieved through such an innovative, experimental approach. Projects and technologies I have described here are easy and affordable to use and, in my judgment, worth trying when our collective goal is to attract the curiosity of people of all ages.

\section{REFERENCES CITED}

Arya, Ali, Peggy Hartwick, Shawn Graham, and Nuket Nowlan

2012 Collaborating through Space and Time in Educational Virtual Environments: 3 Case Studies. Journal of Interactive Technology and
Pedagogy 2. Electronic document, https://jitp.commons.gc.cuny.edu/ collaborating-through-space-and-time-in-educational-virtualenvironments-3-case-studies/, accessed May 18, 2017

British Museum

2014 The British Museum on Sketchfab. Electronic document, https://sketchfab.com/britishmuseum, accessed April 28, 2017.

Campus Archaeology Program

2017 Home. Electronic document, http://campusarch.msu.edu, accessed May 4, 2017.

Copplestone, Tara

2014 Buried! Game Overview. Electronic document, http://www. taracopplestone.co.uk/buriedindex.html, accessed April 28, 2017

Deniau, Guillame

2017a Cultural Heritage Spotlight: Q\&A with Daniel Pett from the British Museum (Part 1). Electronic document, https://blog.sketchfab.com/ cultural-heritage-spotlight-qa-daniel-pett-british-museum-part1/ accessed April 28, 2017

2017b Cultural Heritage Spotlight: Q\&A with Daniel Pett from the British Museum (Part 2). Electronic document, https://blog.sketchfab.com/ cultural-heritage-spotlight-qa-daniel-pett-british-museum-part-2/ accessed April 28, 2017

2017c Cultural Heritage Spotlight: Q\&A with Daniel Pett from the British Museum (Part 3). Electronic document, https://blog.sketchfab.com/ cultural-heritage-spotlight-qa-with-daniel-pett-from-the-british-museumpart-3/, accessed April 28, 2017.

Eve, Stuart

2012 Augmenting Phenomenology: Using Augmented Reality to Aid Archaeological Phenomenology in the Landscape. Journal of Archaeological Method and Theory 19(4):582-600. DOI:10.1007/ s10816-012-9142-7, accessed June 5, 2017.

2017 The Embodied GIS: Using Mixed Reality to Explore Multi-Sensory Archaeological Landscapes. Internet Archaeology 44. DOI: https://doi org/10.11141/ia.44.3, accessed June 21, 2017.

Eve, Stuart, Kerrie Hoffman, Colleen Morgan, Alexis Pantos, and Sam Kinchin-Smith

2014 Voices Recognition. Electronic document, http://www.heritagejam. org/jam-day-entries/2014/7/12/voices-recognition-stuart-eve-kerriehoffman-colleen-morgan-alexis-pantos-and-sam-kinchin-smith, accessed April 28, 2017

Florida Public Archaeology Network

2017 About Us. Electronic document, http://www.flpublicarchaeology.org/ about/, accessed May 4, 2017

Foreman, Joel, James Paul Gee, J. C. Herz, Randy Hinrichs, Marc Prensky, and Ben Sawyer

2004 Game-Based Learning: How to Delight and Instruct in the 21st Century. EDUCAUSE Review 39 (5):50-66.

Giuseppantonio Di Franco, Paola

2015 3D Printing and Immersive Visualization for Improved Perception of Ancient Artifacts. Presence 24(3):243-264.

Giuseppantonio Di Franco, Paola, Justin L. Matthews, and Teenie Matlock

2016 Framing the Past: How Virtual Experience Affects Bodily Description of Artefacts. Journal of Cultural Heritage 17:179-187.

Gonzalez-Tennant, Edward

2011 Archaeological Research and Public Knowledge: New Media Methods for Public Archaeology in Rosewood, Florida. PhD dissertation, Department of Anthropology, University of Florida, Gainesville.

2013 New Heritage and Dark Tourism: A Mixed Methods Approach to Social Justice in Rosewood, Florida. Heritage \& Society 6(1):62-88.

Graham, Shawn

2015 The Diary in the Attic. Electronic document, https:// electricarchaeology.ca/2015/07/16/the-diary-in-the-attic/, accessed April 28, 2017.

Graham, Shawn, Stuart Eve, Colleen Morgan, and Alexis Pantos

2015 Hearing the Past. Electronic document, https://electricarchaeology. ca/2015/01/05/hearing-the-past/ accessed April 28, 2017.

Insole, Peter, and Angela Piccini

2014 Your Place or Mine? Crowdsourced Planning, Moving Image Archives and Community Archaeology. Archäologische Informationen 36:31-43. 
Lithodomos, VR

2017 Ancient Jerusalem in VR. Electronic document, https://lithodomosvr. com/ancient-jerusalem-in-vr/, accessed April 28, 2017.

Milgram, Paul, Haruo Takemura, Akira Utsumi, and Fumio Kishino

1995 Augmented Reality: A Class of Displays on the Reality-Virtuality Continuum. Proceedings of Telemanipulator and Telepresence Technologies 282. DOI:10.1117/12.197321, accessed June 5, 2017.

Morgan, Colleen L.

2009 (Re)Building Catalhoyuk: Changing Virtual Reality in Archaeology. Archaeologies 5(3):468-487.

2016 Pixel vs Pigment: The Goal of Virtual Reality in Archaeology. Electronic document, https://savageminds.org/2016/01/11/pixel-vspigment-the-goal-of-virtual-reality-in-archaeology/, accessed April 28, 2017

Nicholas, George, Catherine Bell, Rosemary Coombe, John Welch, Brian Noble, Jane Anderson, Kelly Bannister, and Joe Watkins

2010 Intellectual Property Issues in Heritage Management Part 2: Legal Dimensions, Ethical Considerations, and Collaborative Research Practices. Heritage Management 3(1):117-147.

Paleowest Archaeology

2016 Little Petroglyph Canyon Mapping Project. Electronic document, https://sketchfab.com/models/500e9b63fafb4be3978557e2ce813834, accessed April 28, 2017.

PIVOTtheWorld, Inc.

2016 Product. Electronic document, http://www.pivottheworld.com/ product, accessed April 28, 2017

Rogers, Kate

2016 Shooting Archaeologists. Off the Record: Archaeology and Documentary Filmmaking Paper presented at the 8th World Archaeological Congress, Kyoto, Japan.
Sims, Lionel

2009 Entering, and Returning from, the Underworld: Reconstituting Silbury Hill by Combining a Quantified Landscape Phenomenology with Archaeoastronomy. Journal of the Royal Anthropological Institute 15:386-408.

Sketchfab

2017 Sketchfab Virtual Reality. Electronic document, https://sketchfab.com/ virtual-reality, accessed April 28, 2017.

Tilley, Christopher

1994 A Phenomenology of Landscape. Berg, Oxford.

Trowbridge, David

2017 Clio FAQs. Electronic document, https://www.theclio.com/web/, accessed April 28, 2017.

Van Dyke, Ruth M

2007 The Chaco Experience: Landscape and Ideology at the Center Place. School for Advanced Research Press, Santa Fe, New Mexico.

2008 Visual Perception in Chaco Canyon, New Mexico: Some Phenomenological Observations. In Archaeology and the Politics of Vision in a Post-Modern Context, edited by Vítor Oliveira Jorge and Julian Thomas, pp. 278-291. Cambridge Scholars Publishing, Cambridge.

Virtual Curation Museum

2013 About the Virtual Curation Museum. Electronic document, https://virtualcurationmuseum.wordpress.com/about/, accessed April 28, 2017.

\section{AUTHOR INFORMATION}

Kate Ellenberger Department of Anthropology, Binghamton University, PO Box 6000, Binghamton, NY 13902-6000, USA (kellenb1@binghamton.edu) 